\title{
Clinical evaluation of the Infrasonde D4000 blood pressure monitor
}

\author{
A. V. Zezulka, P.J.M. Sloan, P. Davies ${ }^{1}$ and D.G. Beevers
}

University Department of Medicine, Dudley Road Hospital, Birmingham B18 7QH, and ${ }^{1}$ Department of Statistics, University of Birmingham, $U K$.

\begin{abstract}
Summary: Choosing a blood pressure machine from their ever increasing number is often difficult due to lack of performance data. We have evaluated a new automated non-invasive blood pressure recorder, the Infrasonde D4000 ${ }^{\circledR}$. In comparison with the Hawksley random zero mercury sphygmomanometer the Infrasonde showed less variability for both systolic and diastolic readings. However, it was found to record significantly lower mean systolic and diastolic pressures.
\end{abstract}

\section{Introduction}

An increasing number of machines are available for the indirect measurement of blood pressure (BP). The conveniences and technical specifications are emphasized in the manufacturers' brochures but data on performance in relation to standard sphygmomanometers are rarely provided. We have evaluated the performance of a new fully automated machine; Puritan Bennett's Infrasonde D4000 ${ }^{\circledR}$ non-invasive blood pressure monitor which the manufacturers consider has facilities making it suitable for all hospital settings.

The Infrasonde D4000 may be operated in fully automatic, semi-automatic or manual mode. It is portable, weighs $7.7 \mathrm{~kg}$, and can operate from mains or integral rechargable batteries. Cuff inflation pressure may be fixed or allowed to change automatically in relation to previous systolic BP. Deflation rate, inflation and deflation cycle frequency are adjustable. Signal strength can be assessed and if poor the transducer may be repositioned or sensitivity increased. Systolic and diastolic BP are shown on separate LED displays. Following deflation heart rate or pulse pressure is displayed. Mean arterial pressure or rate pressure product may also be presented on the LED display. All measurements can be displayed on

A.V. Zezulka, B.Sc., M.R.C.P.; P.J.M. Sloan, B.Med.Sci., M.R.C.P.; P. Davies, M.Sc., Ph.D.; D.G. Beevers, M.D., F.R.C.P.

Correspondence: A.V. Zezulka, Dudley Road Hospital, Birmingham B18 7QH

Accepted: 27 September 1984 an optional integral printer. The measurement range is stated to be from 0 to $300 \mathrm{~mm}$ with adjustable low and high alarm limits. Various cuff sizes together with dual differential and single transducer assemblies are available.

\section{Methods}

Adult static BP measurements were made on 4 consecutive days in 4 groups of subjects. These were from departmental staff, the Hypertension Clinic, the antenatal and general medical wards. The groups were selected to provide a wide range of blood pressures. All measurements were made with recently calibrated machines, the observers having no prior knowledge of the BP. Subjects not in sinus rhythm and those with aortic regurgitation were excluded. Blood pressure was measured by 2 observers (AZ, PS). Simultaneous measurements of blood pressure were taken in opposite arms using different machines (Infrasonde D4000 and Hawksley random zero). Thereafter each observer changed arm and then machine using a previously described crossover technique (Silas et al., 1982; Beevers et al., 1979). Observers were not aware of each other's measurements. Each observer recorded BP in both arms with both machines. A total of 4 pairs of simultaneous BP values were thus obtained per subject. Subjects were seated with their arms relaxed and supported. Identical appropriate occlusion cuff sizes were used. No patients had arm girths requiring large cuffs. The cuff deflation rate was set at $2 \mathrm{~mm}$ per 
pulse. The Infrasonde diastolic value is said to correspond to Korotkoff phase V (disappearance of sounds). Diastolic values read from the Hawksley were therefore taken at phase $\mathrm{V}$ using the bell of the stethoscope. The random zero was not subtracted from the Hawksley readings until the end of the experiment. All Infrasonde measurements were made using its dual differential transducer assembly.

\section{Results}

Twenty-six cases were studied yielding 104 pairs of measurements for systolic and diastolic BP. A scatterplot with line of identity showing simultaneous Hawksley and Infrasonde systolic and diastolic BP measurements was constructed (Figure 1). For systolic pressures the D4000 consistently recorded lower values than the Hawksley. The diastolic pressure relationship appears more complex. At lower values there is a suggestion that the Infrasonde records higher values than the Hawksley. Passing through the range studied this effect reverses.

For each subject the average of the four blood pressure readings resulting from each arm/observer combination was calculated. Linear regression analysis of the Infrasonde averages on the Hawksley averages was then carried out.

Results of regression analysis giving the correlation coefficients between Infrasonde and Hawksley readings using two models are presented in Table $I$.

For systolic and diastolic blood pressure the nonzero intercept (a) does not differ significantly from zero and regression analysis for a line through the origin seems adequate. For both pressures the slope is significantly less than $1(P<0.001)$ and the D4000 value is about 0.95 of the Hawksley.

The results of analysis of variance data are presented in Table II. The Hawksley systolic mean was higher than the D4000 readings in all subjects and the diastolic in 21 of 26 . The average D4000 systolic

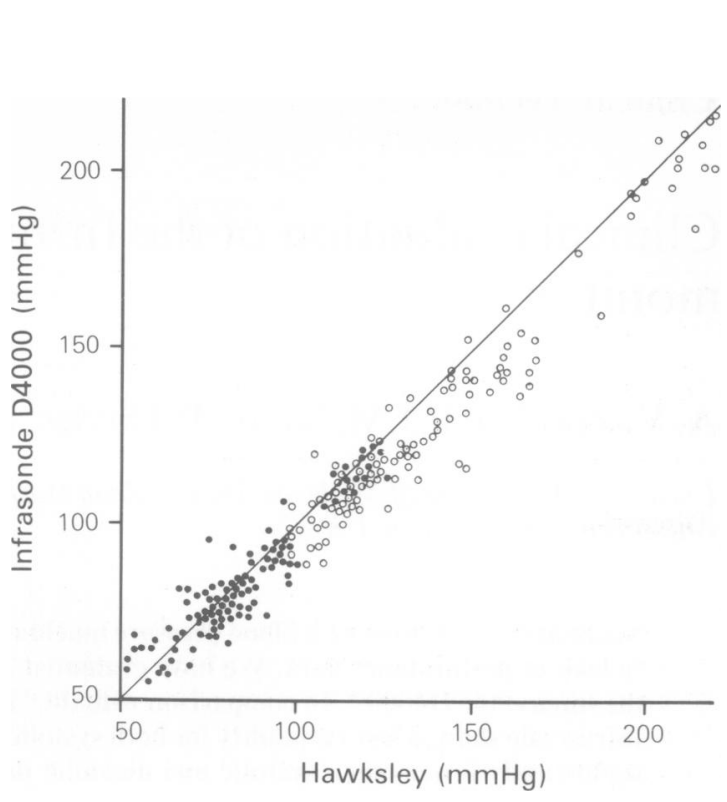

Figure 1 Scatterplot of simultaneous Hawksley and Infrasonde systolic $(\mathrm{O})$ and diastolic $(\Theta)$ blood pressure.

pressures were $8.6 \mathrm{~mm} \mathrm{Hg}$ lower $(P<0.001)$ and diastolic $2.9 \mathrm{~mm} \mathrm{Hg}$ lower $(P<0.05)$ than the Hawksley values. The Infrasonde gave significantly lower standard deviations than the Hawksley. We dief not observe any consistent evidence that the variabilit of results in either machine was different anywhere across the blood pressure range measured.

Using the Infrasonde outside the confines of the experiment we noted two limitations. It does not recognize auscultatory silent gaps and displays systolic pressure as the return of sounds following the gap. Further, no measurement is made when there is a wide pulse pressure and the deflation rate is slow. This can be overcome by increasing deflation rate and presumably relates to artefact rejection devices which demand a sequential systolic and diastolic reading within a time limit.

Table I Correlation coefficient and regression analysis for D4000 and Hawksley blood pressure machines.

\begin{tabular}{|c|c|c|c|c|}
\hline & \multirow{3}{*}{$\begin{array}{c}\text { Correlation coefficient }(r) \\
\text { between Hawksley and Infrasonde } \\
r\end{array}$} & \multirow{2}{*}{\multicolumn{2}{|c|}{$\begin{array}{l}\text { Regression model }(A) \\
\text { non-zero intercept }(a) \\
\text { with slope }(b)\end{array}$}} & \multirow{3}{*}{$\begin{array}{c}\text { Regression model (B) } \\
\text { slope (b) with zero } \\
\text { intercept } \\
b\end{array}$} \\
\hline & & & & \\
\hline & & $a$ & $b$ & \\
\hline Systolic & 0.99 & $\begin{array}{c}-5.85 \\
(\text { s.e. } 4.54)\end{array}$ & $\begin{array}{c}0.98 \\
\text { (s.e. } 0.031)\end{array}$ & $\begin{array}{c}0.94 \\
\text { (s.e. } 0.008 \text { ) }\end{array}$ \\
\hline Diastolic & 0.97 & $\begin{array}{c}+5.94 \\
\text { (s.e. 3.56) }\end{array}$ & $\begin{array}{c}0.91 \\
\text { (s.e. } 0.041)\end{array}$ & $\begin{array}{c}0.97 \\
\text { (s.e. } 0.008)\end{array}$ \\
\hline
\end{tabular}


Table II Table of analysis of variance on all blood pressure values removing variation due to subjects, arms, observers and arm/observer interactions. s.d. $=$ standard deviation $\quad \mathrm{CV}=$ coefficient of variation

\begin{tabular}{lccccccc}
\hline & Mean & $\begin{array}{c}\text { Hawksley } \\
\text { s.d. }(\mathrm{mm} \mathrm{Hg})\end{array}$ & $\mathrm{CV} \%$ & Mean & $\begin{array}{c}\text { D4000 } \\
\text { s.d. }(\mathrm{mm} \mathrm{Hg})\end{array}$ & CV\% & $\begin{array}{c}\text { Differences } \\
\text { in means }\end{array}$ \\
\hline $\begin{array}{l}\text { Systolic } \\
\text { blood pressure }\end{array}$ & 142.3 & 7.2 & 5.1 & 133.8 & 6.4 & 4.8 & $\begin{array}{c}-8.6 \\
(P<0.001)\end{array}$ \\
\hline $\begin{array}{l}\text { Diastolic } \\
\text { blood pressure }\end{array}$ & 84.9 & 5.2 & 6.1 & 82.9 & 4.4 & 5.3 & $\begin{array}{c}-2.9 \\
(P<0.05)\end{array}$ \\
\hline
\end{tabular}

\section{Discussion}

The Hawksley random zero mercury sphygmomanometer (Wright \& Dore, 1970) reduces observer bias, observer error and digit preference which is common when using the standard mercury sphygmomanometer (Grimley Evans \& Prior, 1970). Its simple robust design has led to it being adopted for large scale surveys and research studies where it has achieved the status of a 'gold standard'. These clinical trials provide guidelines for clinical practice. Automated blood pressure recorders should provide a similar advantage of increased objectivity in measurement and should free the operator to perform other tasks. However, measurements produced by these machines should be strictly comparable.

The results show that the Infrasonde D4000 records lower mean systolic and diastolic blood pressures than the Hawksley. The offset of Infrasonde diastolic pressures is not constant with over-reading at lower pressures and under-reading at higher diastolic values. These differences reach statistical significance and may be important when deciding therapy in mild hypertension. Changes in blood pressure are frequently of greater interest than absolute values and the lower variability of readings should be an advantage for the Infrasonde machine.

The difference in performance might be explained by the way in which information for measurement is acquired. Both methods aim at Korotkoff phase I for systolic and phase V for diastolic pressure. The Infrasonde microphone frequency response is between 10 and $50 \mathrm{~Hz}$ (manufacturer's data). The frequency range of Korotkoff I sounds is reported to be between 40 and $120 \mathrm{~Hz}$ with maximum amplitude centred

\section{References}

BEEVERS, D.G., BLOXHAM, C.A., BACKHOUSE, C.I., LIM, C.C. \& WATSON R.D.S. (1979). The Remler M2000 semiautomatic blood pressure recorder. British Heart Journal, 42, 366.

GRIMLEY EVANS, J. \& PRIOR, I.A.M. (1970). Experience with the random zero sphygmomanometer. British Journal of Preventive and Social Medicine, 24, 10.

MCCUTCHEON, E.P. \& RUSHMER, R.F. (1967) Korotkoff around $100 \mathrm{~Hz}$. Upon muffling (phase IV) the higher frequencies are attenuated and the maximum amplitude then centres around $60 \mathrm{~Hz}$ (McCutcheon \& Rushmer, 1967). The fundamental frequency of oscillation is between 12 and $50 \mathrm{~Hz}$ with the frequency increasing as the pressure difference between compression and upstream brachial arterial pressure decreases (Ur \& Gordon, 1970). The amplitude of this frequency is directly related to flow magnitude. Thus one possible explanation for the lower measurements obtained by the Infrasonde may be related to its inability to detect higher frequencies. On occasions it may be due to failure to detect the silent gap. Higher diastolic values produced by the Infrasonde at the lower end of the diastolic range might be explained in terms of microphone insensitivity. The Infrasonde microphone is a piezo electric device and these are generally very sensitive. An alternative explanation could lie with processing of the signal for artefact rejection.

\section{Addendum}

The cost exclusive of VAT is approximately $£ 2150$. The printer costs an additional $£ 660$. The Infrasonde D4000 ${ }^{\circledR}$ is marketed by Simonsen and Weel Ltd, Unit 1 Ruxley Corner, Sidcup, Kent.

\section{Acknowledgement}

We are grateful to Miss Verdelle Osbourne for secretarial work.

sounds: an experimental critique. Circulation, 20, 149.

SILAS, J.H., BARKER, A.T. \& RAMSAY, L.E. (1980). Clinical evaluation of Cinamap 845 automated blood pressure recorder. British Heart Journal, 43, 202.

UR, A. \& GORDON, M. (1970). Origin of Korotkoff sounds. American Journal of Physiology, 218, 524.

WRIGHT, B.M. \& DORE, C.F. (1970). A random zero sphygmomanometer. Lancet, i, 337. 